\title{
Breve caminhada com uma bengala e reflexões sobre o universo material do público sênior
}

Strolling with a walking stick - reflections on the material environment of aged people

\section{Vera Maria Damazio}

Universidade Estadual do Rio de Janeiro - UERJ

vdamazio@puc-rio.br

Luiza Beck Arigoni

Universidade Estadual do Rio de Janeiro - UERJ

luizaarigoni@hotmail.com $\mathbf{x}$

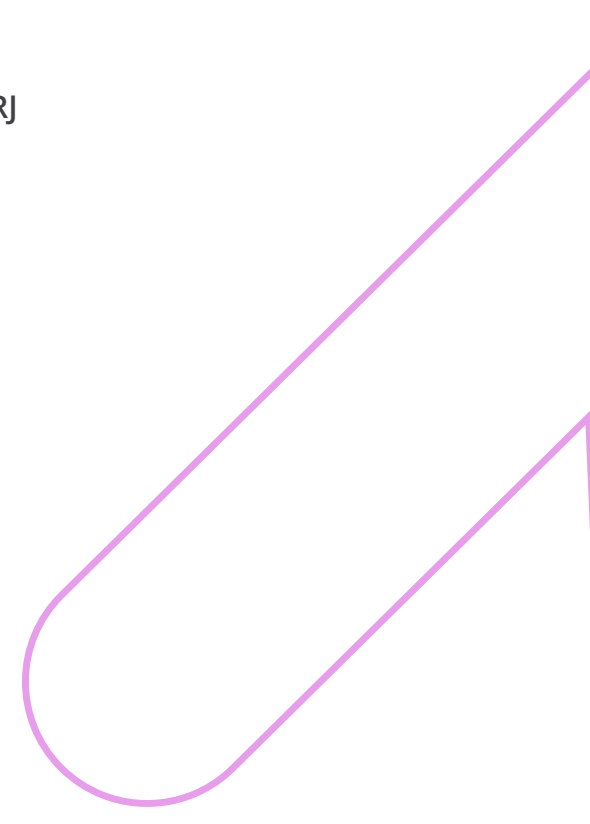

\section{PROJËTICA}

\section{COMO CITAR ESTE ARTIGO:}

DAMAZIO, V. M.; ARIGONI, L. B. Breve caminhada com uma bengala e reflexões sobre o universo material do público sênior. Projética, Londrina, v. 11, n. 1, p 220244, 2020.

DOI: $10.5433 / 2236-2207.2020 v 11 n 1 p 220$

Submissão: 13-03-2019

Aceite: 05-06-2019 
RESUMO: Estamos envelhecendo e vivendo cada vez mais. Fenômeno crescente e irreversível, o envelhecimento da população é um dos maiores desafios do século XXI e abre importante e inexplorado campo de atuação para o Design. Este artigo foi fundamentado em levantamento bibliográfico sobre o processo do envelhecer e estudos com base no método de observação participante junto ao público sênior. Ele apresenta dados sobre o envelhecimento populacional e a trajetória da bengala desde seus primórdios até os tempos atuais e traz reflexões a respeito da relação entre as pessoas e os artefatos e do universo material projetado para o público sênior.

Palavras-chave: Design. Velhice. Longevidade. Público sênior. Idosos.

ABSTRACT: We are aging and living more and more. The irreversible increasing of the aged population is one of the greatest challenges of the 21st century and opens up an important and unexplored field of action for Design. This paper is supported by a bibliographical survey about the aging process and a participant observation study on the aged audience. It presents data on population aging and the history of walking sticks from its earliest moments to present times, evoking reflections on the relationship between people and artifacts and the material universe designed for the aged audience.

Keywords: Design. Aging. Longevity. Material culture. Aged audience.

\section{INTRODUÇÃO}

O envelhecimento demográfico em ritmo acelerado está ocorrendo em muitas partes do mundo. A cada segundo duas pessoas completam 60 anos, resultando em quase 58 milhões de novos sexagenários por ano e nos últimos 50 
Projética, Londrina, v.11, n.1, p. 220-244, abril 2020

anos, a expectativa de vida global aumentou mais do que ao longo dos 5000 anos anteriores. A exemplo do envelhecimento, a longevidade da população também cresce aceleradamente. Em 2050, o planeta contará pela primeira vez em sua história, com mais idosos do que crianças com menos de 15 anos, contabilizando um em cada cinco de seus habitantes com idade igual ou maior a 60 anos (UNITED NATIONS POPULATION FUND; HELPAGE INTERNATIONAL, 2012).

A velhice pode ser entendida a partir de várias perspectivas. Sob o ponto de vista biológico, abrange as alterações fisiológicas, hormonais, anatômicas e bioquímicas do organismo, assim como questões referentes à herança genética e ao ambiente em que se deu o processo de envelhecimento. Já sob o ponto de vista antropológico, tanto a velhice quanto aqueles que a vivenciam são considerados construções socioculturais e mutáveis de acordo com as coordenadas históricas e geográficas em que se manifestam (BEAUVOIR, 1990; DEBERT, 1999; GOLDENBERG, 2013).

Seja qual for a perspectiva, é comum e recorrente a percepção de que o envelhecimento é um processo marcado por mais perdas do que ganhos e a velhice é um estágio da vida sobre o qual pesam muito mais aspectos negativos do que positivos. Os velhos, por sua vez, tendem a ser percebidos como indivíduos dependentes, vulneráveis e improdutivos. Etapas da vida como a infância, a adolescência e a maturidade são saudadas por produtos e serviços diversos e em frenética renovação. Já a velhice é recepcionada por abreviado universo material sem grande variação e mais comumente voltado para as perdas e limitações físicas.

Contudo, a considerável parcela da população que cruza o marco dos 60 anos abrange personalidades, necessidades, comportamentos e estilos de vida bastante diferentes, é diversa, plural e apresenta número maior de singularidades do que qualquer outro grupo etário. Cabe, neste ponto, ressaltar que a velhice pode ser a mais longa fase da vida e durar muitas décadas. Além de extremamente 
heterogêneos, vale ressaltar que em breve os maiores de 60 serão mais numerosos do que o público infantil, como apontam projeções demográficas. No entanto, quanto mais avançam na extensa fase da vida chamada velhice e aumentam, mudam e diversificam suas demandas, mais veem diminuídas as opções de produtos e serviços para atendê-los. Em resumo, a população com mais de 60 está aumentando, vivendo mais, mas não está tendo suas demandas entendidas, nem atendidas a contento. Como bem resume Simone de Beauvoir (1990, p. 345), "a velhice é o que acontece às pessoas que ficam velhas; impossível encerrar essa pluralidade de experiências num conceito, ou mesmo numa noção". Podemos concluir que é impossível, tampouco, encerrar essa pluralidade em um universo reduzido de produtos e serviços.

O envelhecimento da população global é resultado, entre outros fatores, da diminuição das taxas de mortalidade precoce e do aumento da expectativa de vida em grande parte do mundo, e não à toa vem sendo considerado um dos maiores triunfos do século XXI e motivo de celebração (UNITED NATIONS POPULATION FUND; HELPAGE INTERNATIONAL, 2012). Esta realidade inédita se estenderá a um em cada cinco habitantes no planeta em poucas décadas e apresenta-se como oportunidade ímpar a ser explorada pelo Design, atividade de natureza interdisciplinar instrumentada para identificar e desenvolver soluções para demandas sociais complexas e transformar realidades existentes em outras mais desejáveis (FRASCARA, 2004; SIMON, 1969).

\section{SOBRE PESSOAS E ARTEFATOS: UMA ESTREITA E VITAL RELAÇÃO}

Os utensílios de pedra lascada ilustram o início de nosso convívio com os artefatos e uma de nossas principais diferenças em relação aos demais seres vivos: nossa capacidade de fazer, de usar e dar significados às coisas, e desenvolver extensões materiais para tudo aquilo que costumávamos fazer com o nosso próprio corpo. Como bem ilustra o antropólogo Edward T. Hall (1977, p. 21): 
Projética, Londrina, v.11, n.1, p. 220-244, abril 2020

A evolução de nossas armas começa pelos dentes e punhos e termina com a bomba atômica. Indumentária e casas são extensões dos mecanismos biológicos de controle de temperatura do corpo. A mobília substitui o acocorar-se e sentar-se no chão. Instrumentos mecânicos, lentes, televisão, telefones e livros que levam a voz através do tempo e do espaço constituem exemplos de extensões materiais.

A trajetória da humanidade vem sendo marcada por nossa relação com o entorno material e, também, pela natureza e modos por meio dos quais somos capazes de produzir nossos artefatos: o Paleolítico nomeia a longa fase de criação e uso de utensílios de pedra lascada; o Neolítico, o período dos utensílios de pedra polida; a Era do Bronze e a Era do Ferro descrevem tempos em que os objetos passam a ser moldados em metal; a Revolução Industrial, a Era Atômica e a Era Digital sinalizam períodos de transição e mudança dos modos de produção (COELHO, 2002; ROCHE, 1998).

É fato inegável e evidente que nossa existência sempre esteve e está, como nunca antes, atrelada aos artefatos que nos rodeiam. Produzidos unitariamente, em pequena escala ou ad infinitum, é inconcebível imaginarmo-nos, hoje, sem as "extensões" que desenvolvemos para atender nossas necessidades, das mais simples às mais complexas, das mais mecânicas às mais emocionais. Não vivemos apenas atrelados, mas graças a artefatos. E dentre eles decerto encontram-se algumas "chaves" para o entendimento da sociedade contemporânea, pois, como nos apresenta a renomada filósofa e estudiosa de temas do cotidiano, Agnes Heller (1972, p. 17):

[...] a vida cotidiana é a vida de todo homem. Todos a vivem, sem nenhuma exceção, qualquer que seja seu posto na divisão do trabalho intelectual e físico [...] é a vida do homem inteiro; ou seja, o homem participa na vida cotidiana com todos os aspectos de sua individualidade, de sua potencialidade. 
Tal como defendem autores de variados campos do saber, os artefatos têm participação ativa na vida cotidiana, e são usados pelas pessoas para estabelecer significados sobre si mesmas e suas vidas, chegando, em algumas circunstâncias, a ser o eixo em torno do qual as ações sociais se desenrolam. Inter-relacionados com outras engrenagens, os artefatos instruem os indivíduos acerca do mundo, organizam e regulamentam práticas sociais, influenciam comportamentos e provocam efeitos reais e variados. Eles são inseparáveis daquilo que somos e dão forma a nossa identidade. Assim sendo, da mesma forma que fazemos e usamos artefatos, somos, em grande extensão, feitos e usados pelos artefatos e reflexo deles (CERTEAU, 1994; CSIKSZENTMIHALYI; ROCHBERG-HALTON, 1991; DOUGLAS; ISHERWOOD, 2004).

A bengala, e principal protagonista deste artigo, está entre os artefatos mais intimamente associados à velhice. Está, também, entre os mais antigos no cotidiano da humanidade, tendo se dado a usos e, sobretudo, a significados diversos como será apresentado a seguir.

\section{SOBRE PESSOAS E BENGALAS: UMA ANTIGA E ESCLARECEDORA RELAÇÃO}

As bengalas acompanham nossos antepassados há milênios e já acumularam vários nomes, funções, formas, materiais e significados ao longo de sua longa existência. Galhos de madeira de diversos tamanhos e formatos estavam entre as mais versáteis e disponíveis ferramentas das sociedades nômades préhistóricas e funcionavam como extensões do alcance, da força e do equilíbrio dos nossos ancestrais (HALL, 1977). A partir do uso do fogo e de instrumentos afiados, a madeira, por exemplo, passou a tomar formas variadas e atender diferentes propósitos como a coleta de frutos, a caça de animais, a autodefesa, alavancas, base de tendas e apoio à marcha dos grupos por longas distâncias e terrenos inóspitos. 
Projética, Londrina, v.11, n.1, p. 220-244, abril 2020

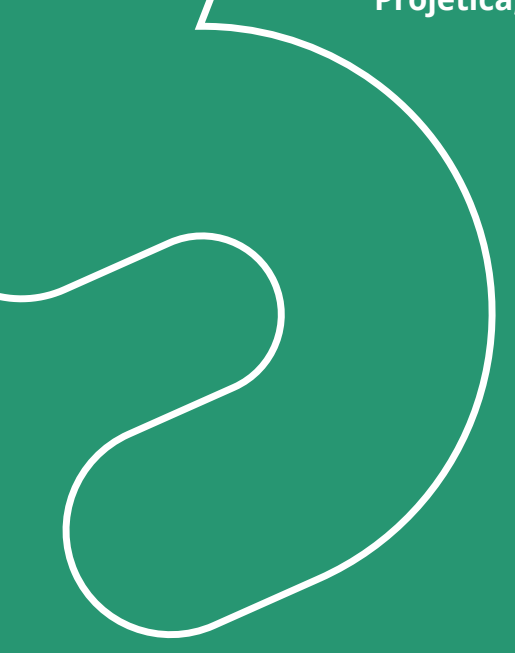

[...] "a velhice é o que acontece às pessoas que ficam velhas; impossível encerrar essa pluralidade de experiências num conceito, ou mesmo numa noção". Podemos concluir que é impossível, tampouco, encerrar essa pluralidade em um universo reduzido de produtos e serviços. 
Breve caminhada com uma bengala e reflexões... público sênior

DAMAZIO, V. M.; ARIGONI, L. B.

\subsection{Pessoas, Bengalas e Poder}

Os registros da relação entre pessoas e bengalas remontam aos primórdios da história. A passagem bíblica da sarça ardente, no livro do Êxodo do Antigo Testamento, relata que Moisés pastoreava um rebanho com um cajado, quando Deus se revelou para orientá-lo na libertação dos hebreus da escravidão. Diante da insegurança de Moisés, Deus transformou o cajado em cobra e, em seguida, em cajado novamente. Esta demonstração de poder foi repetida por Moisés diversas vezes para atestar seu papel como intercessor divino. Segundo as escrituras, foi com o cajado que o profeta liderou o êxodo do Egito, fez brotar água das rochas e abriu o Mar Vermelho para a travessia dos judeus à Terra Prometida (BÍBLIA, Êxodo, 3-4).

Muitos povos da antiguidade representaram seus soberanos e deuses carregando bastões. A crença egípcia sobre vida após a morte teve dentre suas consequências, a preparação de tumbas providas com objetos para atender as necessidades do morto em sua existência pós-morte. Na câmara funerária do faraó egípcio Tutankhamon, descoberta praticamente intacta, foram encontrados bastões de diversas formas e materiais, indicando significados como nobreza, autoridade e poder divino. Alguns deles traziam esculpidas representações de povos inimigos amarrados e humilhados, em uma clara demonstração de soberania (LESTER; OERKE, 2004; SNODGRASS, 2014; ZAKI; PRESS, 2007).

Divindades da Antiga Grécia foram representadas portando bastões, em referência a seus poderes sobre-humanos. Nas imagens retratando Hermes, o veloz deus grego está sempre portando seu caduceu - bastão com duas serpentes entrelaçadas e adornado com asas na parte superior - em referência a seu papel de mensageiro dos deuses, intermediário entre deuses e mortais e deus do comércio, da eloquência, da comunicação, das viagens e da diplomacia (LESTER; OERKE, 2004). 
Projética, Londrina, v.11, n.1, p. 220-244, abril 2020

Figura 1 - "Mercúrio aparece para Aeneas em sonho" de Giovanni Domenico Tiepolo

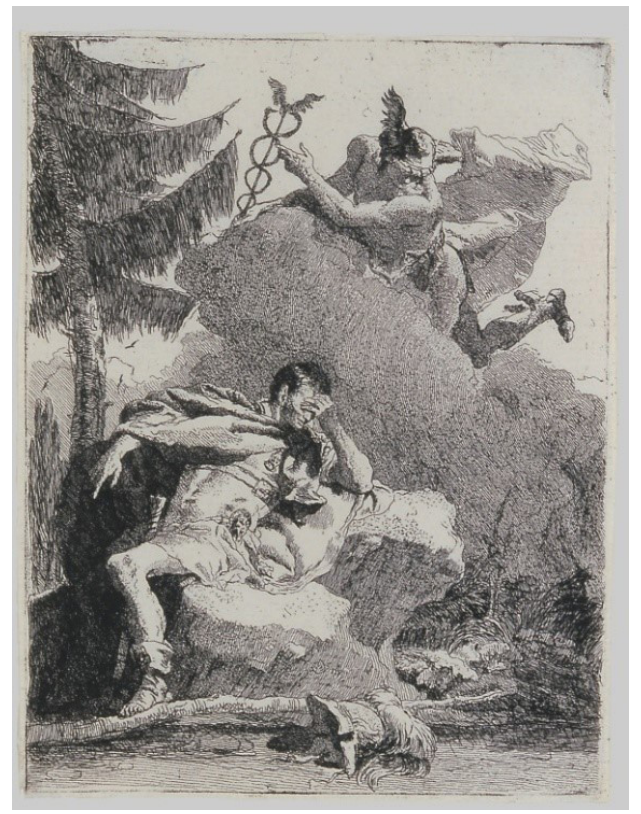

Fonte: Tiepolo (1757).

$\mathrm{Na}$ China Antiga, o bastão de madeira de pessegueiro servia para expulsar influências nefastas por ocasião da chegada do novo ano e o bastão vermelho para a punição dos culpados (CHEVALIER; GHEERBRNT, 2009).

No Império Romano, bastões feitos com galhos de videira, chamados vitis, eram usados para liderar e punir soldados e acabaram tornando-se símbolo da autoridade militar do imperador e emblema da centúria que cada centurião representava e protegia.

Profetas eram reconhecidos por seus lituus, bastões rituais espiralados, e viajantes e peregrinos carregavam bastões como apoio à marcha e autodefesa em suas jornadas realizadas individualmente ou em grupo (LESTER; OERKE, 2004). 
Na Parábola do Bom Pastor (BíBLIA, João, 10, 11-18), Jesus se apresenta como aquele que conhece e dá a vida por cada uma das suas ovelhas e os pastores usavam cajados para manter os rebanhos em ordem e protegê-los de predadores e ladrões. Essa alegoria deu origem ao uso dos bastões episcopais por parte da igreja a partir da Idade Média. Ricos em ornamentações, os bastões episcopais são compostos por três partes com formas e funções distintas: (1) o topo, geralmente encurvado, indica a incumbência de chamar as ovelhas errantes para a Igreja; (2) a haste simboliza a obrigação do bispo de erguer-se firmemente pelo rebanho de fiéis e (3) a base, pontiaguda, incita os indiferentes à fé (LESTER; OERKE, 2004; MORRISROE, 1908; SNODGRASS, 2014).

Na cerimônia de coroação, além da coroa, os reis franceses recebiam como insígnia do poder real, o cetro régio que conferia ao rei comando, força e autoridade e a "mão da justiça", bastão com mão esculpida em marfim que assegurava o papel de primeiro juiz e o poder de julgar, condenar e absolver (LESTER; OERKE, 2004).

\subsection{Pessoas, Bengalas e Distinção}

A partir do século XV, os bastões com ponta recurva passam a ser utilizados como adereço e acessório de moda. No século XVII, ganharam comprimento, ficando mais próximos da altura dos modelos atuais. Os bastões foram, também, acrescidos de fitas e alças decoradas, pelas quais se passavam os pulsos com o propósito de trazer mais conforto e ganharam formatos de T ou J invertido de modo a garantir maior segurança. Também passaram a ser produzidos com ponteiras em metal, para evitar que a madeira se estilhaçasse em contato com o chão. Os espaços ocos das hastes passaram a ser utilizados, como ilustram as bengalas-espadas que derivam de contexto social em que pessoas importantes estavam sujeitas a sofrer ataques (LESTER; OERKE, 2004). 
Projética, Londrina, v.11, n.1, p. 220-244, abril 2020

Figura 2 - "Napoleon sur le throne imperial" de Jean-Auguste-Dominique Ingres e detalhe da "Mão da Justiça" de Martin-Guillaume Biennais
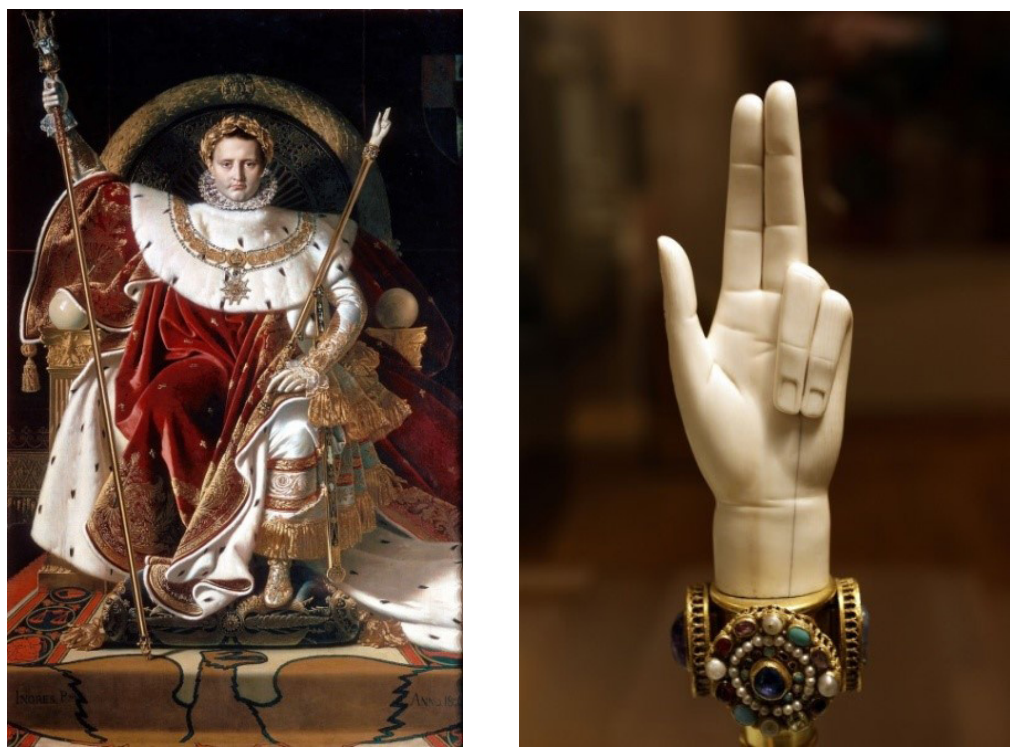

Fonte: Ingres (1806) e Biennais (1804).

A origem da palavra bengala em português vem do antigo Reino de Bengala, região no nordeste da Ásia meridional, onde as primeiras bengalas em cana da Índia foram produzidas e exportadas. Em inglês, são utilizados os termos "walking cane" e "walking stick". Alguns historiadores e colecionadores fazem distinção entre termos, com base na geolingüística, usando a palavra canes na América e sticks na Europa. Outros fazem distinção com base nas matérias-primas com as quais as bengalas foram confeccionadas, usando o termo cane para as produzidas com vegetação tropical e stick para as produzidas como materiais mais nobres, como madeira e marfim (STEELE, 2005).

O uso da bengala passou a ditar regras de etiqueta. Não era de bom tom, por exemplo, apoiar-se sobre a bengala ou carregá-las sob o braço. E jamais deveriam ser utilizadas em dias santos ou visitas a pessoas importantes, pois 
estavam associadas à autoridade e posição social. As bengalas foram se tornando artigos essenciais para o vestuário masculino, mas as mulheres também passaram a portar modelos delicados e ornamentados, e mesmo sombrinhas com a dupla função de proteção do sol e apoio à marcha (LESTER; OERKE, 2004).

Até o final do século XX, governantes, militares, integrantes da igreja e da academia, entre outros em exercício de altos cargos, carregaram algum tipo de bastão em sinal de suas posições de destaque.

\subsection{Pessoas, Bengalas, Popularização e Estigma}

A transição da bengala, de objeto de poder e distinção para objeto popular e estigmatizado foi resultado de uma série de transformações, que influenciaram a produção de bens, a estrutura da sociedade e os padrões de consumo.

Novas tecnologias e materiais transformaram e aceleram o processo de produção e passaram a ser amplamente usados em diversos setores. A produção em massa barateou e possibilitou o consumo de artefatos antes restrito aos abastados, também à classe média ascendente. Acessíveis e resistentes, materiais então desconhecidos como os plásticos e o alumínio estão entre os principais utilizados até hoje na fabricação de bengalas. E se antes, o uso de uma bengala sinalizava poder e pertencimento a um grupo distinto, sua multiplicação acabou dificultando o reconhecimento de pares dentro da sociedade e criando a necessidade de se buscar outras formas de se distinguir da massa (CARDOSO, 2008; DOUGLAS; ISHERWOOD, 2004; LESTER; OERKE, 2004).

A partir do século XVIII, as bengalas passam a assumir novas e inusitadas funções: compartimentos para bebidas, cosméticos, rapé, remédios, pena, tinta e papel, telescópios, talheres, armas de fogo, instrumentos musicais de sopro e cordas, caixas de músicas, rádios e até mesmo instrumentos de choque foram 
Projética, Londrina, v.11, n.1, p. 220-244, abril 2020

algumas das inovações que se deram. A diversificação de formas e de funções da bengala contribuiu para a popularização do acessório e, consequentemente, para a dissociação com poder e distinção (LESTER; OERKE, 2004; ROBITAILLE, 2010; SNODGRASS, 2014).

Figura 3 - Bengala-Espada do século XIX (Metropolitan Museum, Nova lorque, EUA) Bengala-Violino, século XIX (Museum of Fine Arts, Boston, EUA)
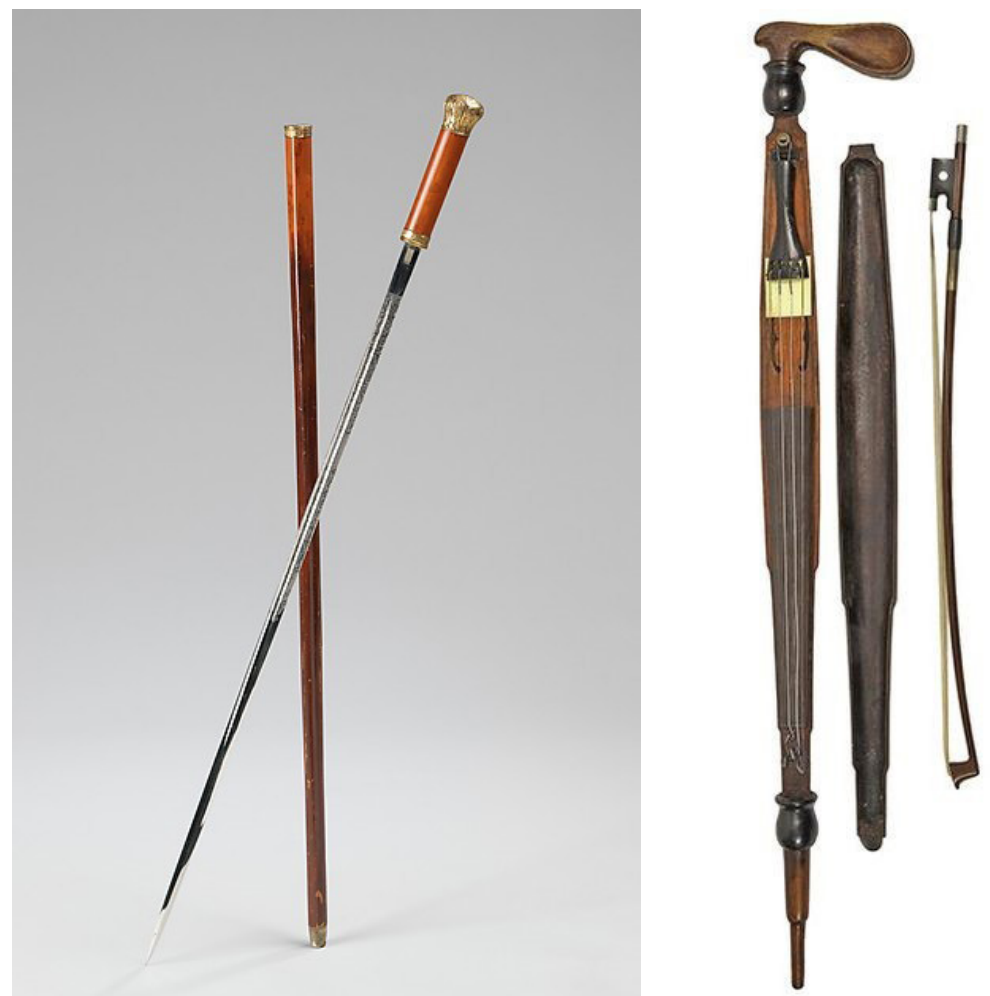

Fonte: Metropolitan Museum of Art (2018) e Museum of Fine Arts (2018)

O declínio mais acentuado do status da bengala se deu no período entre guerras e particularmente no final da Segunda Guerra Mundial. Em tempos de paz, os militares dispensaram o uso dos bastões como sinal de autoridade. O retorno de soldados dos campos de batalha e os danos dos bombardeios em muitas 
cidades da Europa, por sua vez, aumentaram significativamente o contingente de portadores de deficiências físicas e, como resultado, o uso de artefatos que os ajudassem a superar suas limitações. Foi neste contexto que se deu a criação das bengalas brancas, utilizadas por pessoas com deficiência visual, e das bengalas com quatro pontas, utilizadas por pessoas com comprometimento da mobilidade e da estabilidade (LESTER; OERKE, 2004; ROBITAILLE, 2010; SNODGRASS, 2014; STEELE, 2005).

A conjunção de fatos como a massificação da produção de bens, a popularização do consumo, a eficiência das novas alternativas de transporte e portabilidade de objetos pessoais e o triste e elevado saldo de mutilados e portadores de limitações físicas das guerras mundiais contribuíram para que a bengala perdesse seu papel de poder e distinção e se tornasse menos atrativa como acessório utilitário e de moda. Logo, seu uso e imagem foram ficando cada vez mais aderidos à dependência, deficiência física e fragilidade e menos associados à elegância e posição favorável e destacada socialmente.

O uso da bengala com o propósito de ampliar as capacidades funcionais de pessoas com deficiências permanentes ou temporárias suscitou, também, o desenvolvimento e produção de objetos com mais ênfase e atenção aos aspectos mecânicos e econômicos do que aos aspectos estéticos e emocionais, e, por consequência, pouco atraentes e bastante semelhantes entre si.

\subsection{Bengalas Contemporâneas: Assistir e Distinguir}

A Organização Mundial da Saúde estima que mais de um bilhão de pessoas, hoje, precisam de produtos assistivos e que em 2050 este número dobrará para mais dois bilhões, em face do envelhecimento e aumento de expectativa de vida da população mundial. Produtos assistivos, tal como são largamente utilizadas as bengalas atualmente em grande parte do planeta, são cruciais para a longevidade 
Projética, Londrina, v.11, n.1, p. 220-244, abril 2020

com qualidade, na medida em que possibilitam que as pessoas superem suas limitações físicas e tenham um vida produtiva, independente e digna (OMS, 2017).

Tendo em vista a diversidade do público com mais de 60 anos e a parcela de usuários que se valem deste artefato milenar, as bengalas não somente podem, como devem voltar a ser marcas de distinção, empoderamento e individualidade.

Mais recentemente, modelos inovadores e diferenciados têm aparecido no mercado como opção às bengalas e demais suportes para fins assistivos, buscando atender à grande variedade de estilos de vida e demandas dos seus usuários em geral, como apresentado a seguir:

Em projeto de tese intitulado "Proaesthetics", a designer italiana Francesca Lanzavecchia explorou as possibilidades estéticas e expressivas de produtos para fins assistivos. Como resultado, artefatos médicos e ortopédicos associados à deficiência como cintas, bengalas, muletas, órteses e próteses tomaram a forma de golas rendadas, luvas e coletes multifuncionais, espartilhos sensuais, oferecendo opções mais diversificadas e ajustadas ao extenso e variado público que busca compensar ou reduzir as consequências de perda ou declínio de suas capacidades físicas e funcionais.

Apresentando seu estúdio "Lanzavecchia + Wai | Italy \& Singapore" em parceria com o designer Hunn Wai de Singapura, Lanzavecchia esclarece que seu principal interesse está na relação que os objetos estabelecem e podem estabelecer com o corpo e a alma das pessoas. Wai, por sua vez, revela que é "fascinado pelas colisões e fusões de materiais, significados e formas". Na seção dedicada à apresentação dos projetos desenvolvidos pelo estúdio, a premiada dupla de jovens designers reconhece a bengala como um dos objetos mais icônicos e associados à deficiência, e usado em qualquer estágio de doenças ou lesões por uma grande quantidade de pessoas. Lanzavecchia e Wai explicam que as bengalas por eles 
Breve caminhada com uma bengala e reflexões... público sênior

DAMAZIO, V. M.; ARIGONI, L. B.

projetadas foram "reinterpretadas como extensões do corpo, externalizações do processo que o corpo está realizando ou como verdadeiros móveis" como pode ser observado nos exemplos abaixo (LANZAVECCHIA; WAI, 2018).

Figura 4 - Suportes para pescoço em estilo vitoriano e com ganchos e suporte para celular
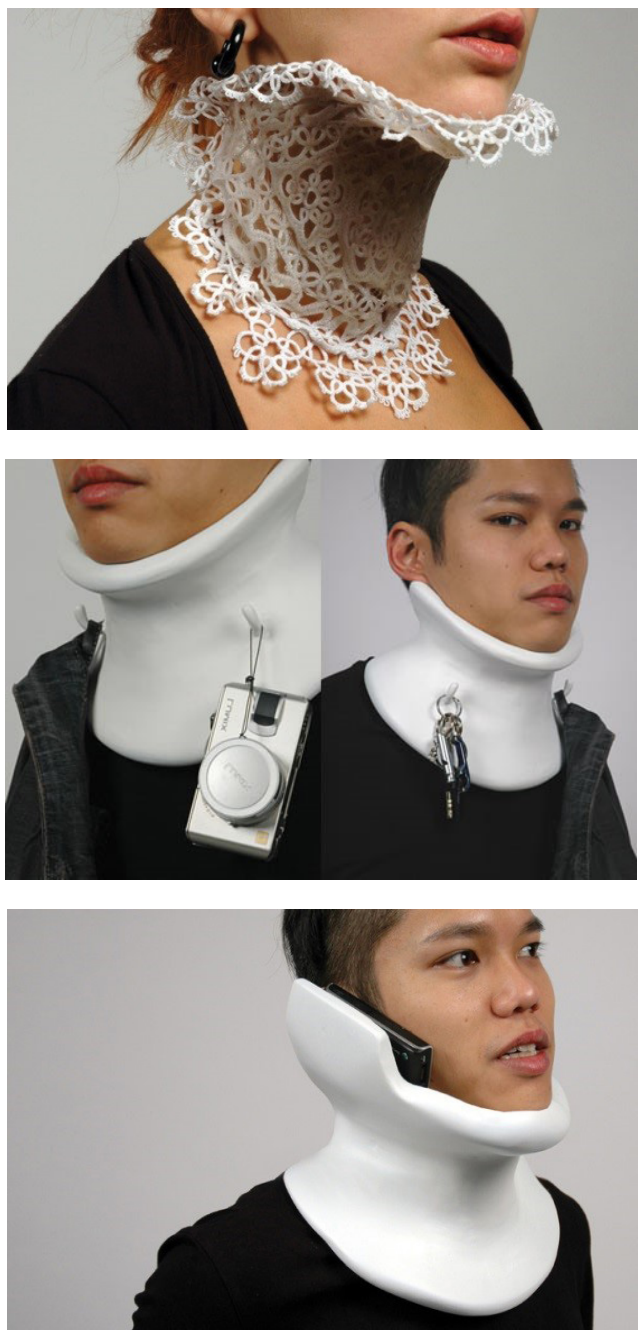

Fonte: Lanzavecchia e Wai (2008). 
Projética, Londrina, v.11, n.1, p. 220-244, abril 2020

Figura 5 - Mobilizador de braço com abridor de garrafas e colete ortopédico

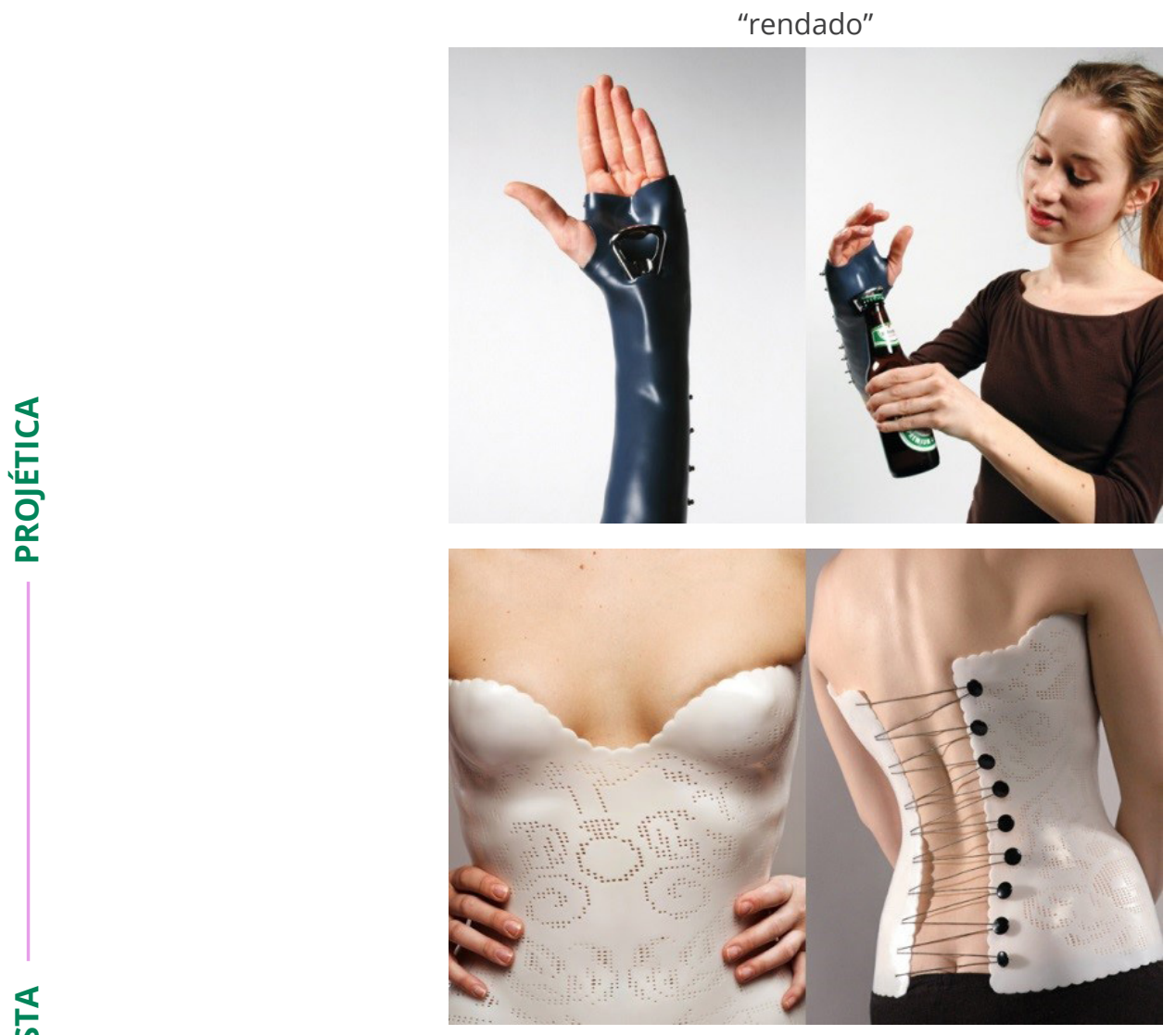

Fonte: Lanzavecchia e Wai (2008).

O produto nomeado "Protaction" (Protação) simula a estrutura óssea, podendo se estender diretamente do ombro ou se encaixar no antebraço de seu portador. A “Tea-Time” (Hora do Chá) é descrita como uma bengala com propriedade de móveis e/ou um móvel com capacidade de dar suporte ao corpo. Lanzavecchia e Wai explicam que "os limites são borrados nesta bengala tripé que traz suporte aos pequenos intervalos do cotidiano, devolvendo a independência e o prazer de pequenos rituais ao seu usuário" (LANZAVECCHIA; WAI, 2018). 
Figura 6 - As bengalas "Protaction" e "A Hora do Chá".
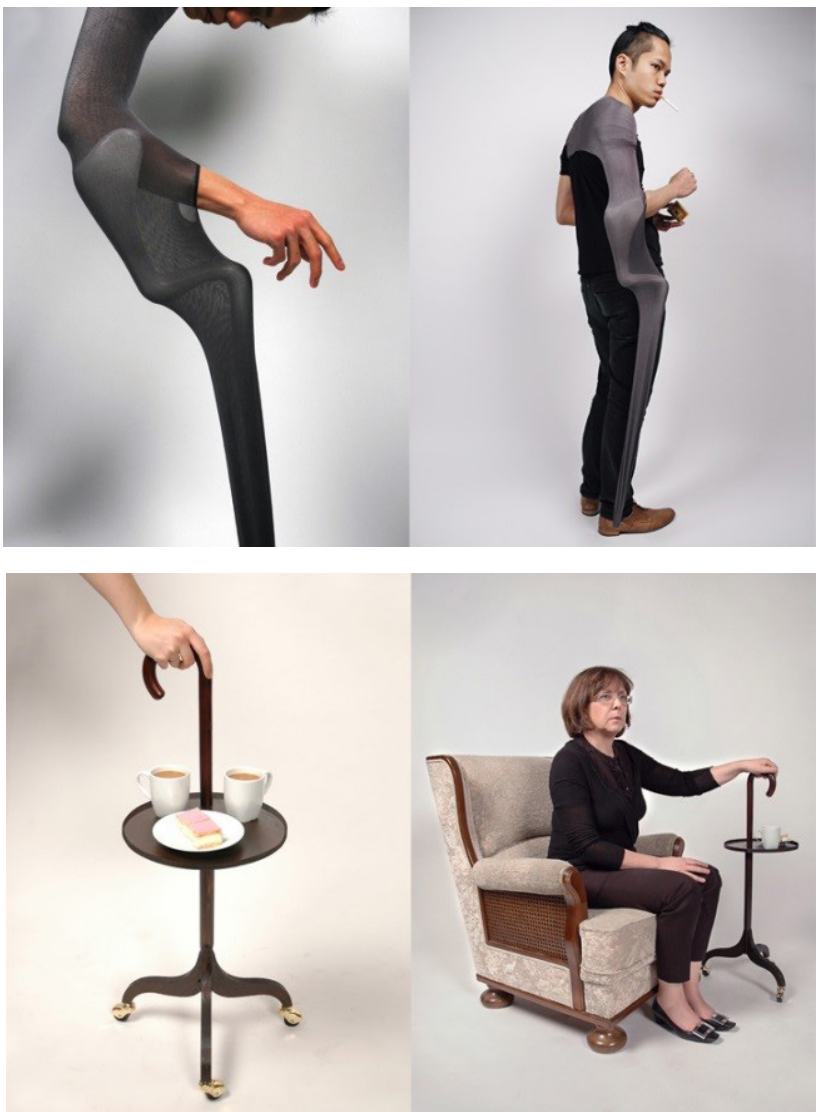

Fonte: Lanzavecchia e Wai (2018).

A bengala "Brittle" (Frágil), de acordo com descrição de seus criadores, "manifesta os sintomas que afligem aqueles que sofrem com ossos quebradiços" e trata-se de um objeto de aparência delicada, mas ao mesmo tempo forte o suficiente para suportar o peso corporal de seus portadores. A bengala "Exo-Hip", por sua vez, teve sua forma inspirada na "beleza de uma reposição de articulação do quadril" e sua releitura como um auxílio para andar. A intenção dos designers foi transformar o que entendem como "um icônico símbolo de curas artificiais" em "um retrato da condição corporal" (LANZAVECCHIA; WAI, 2018). 
Projética, Londrina, v.11, n.1, p. 220-244, abril 2020

Figura 7 - As bengalas "Brittle" e "Exo-Hip".
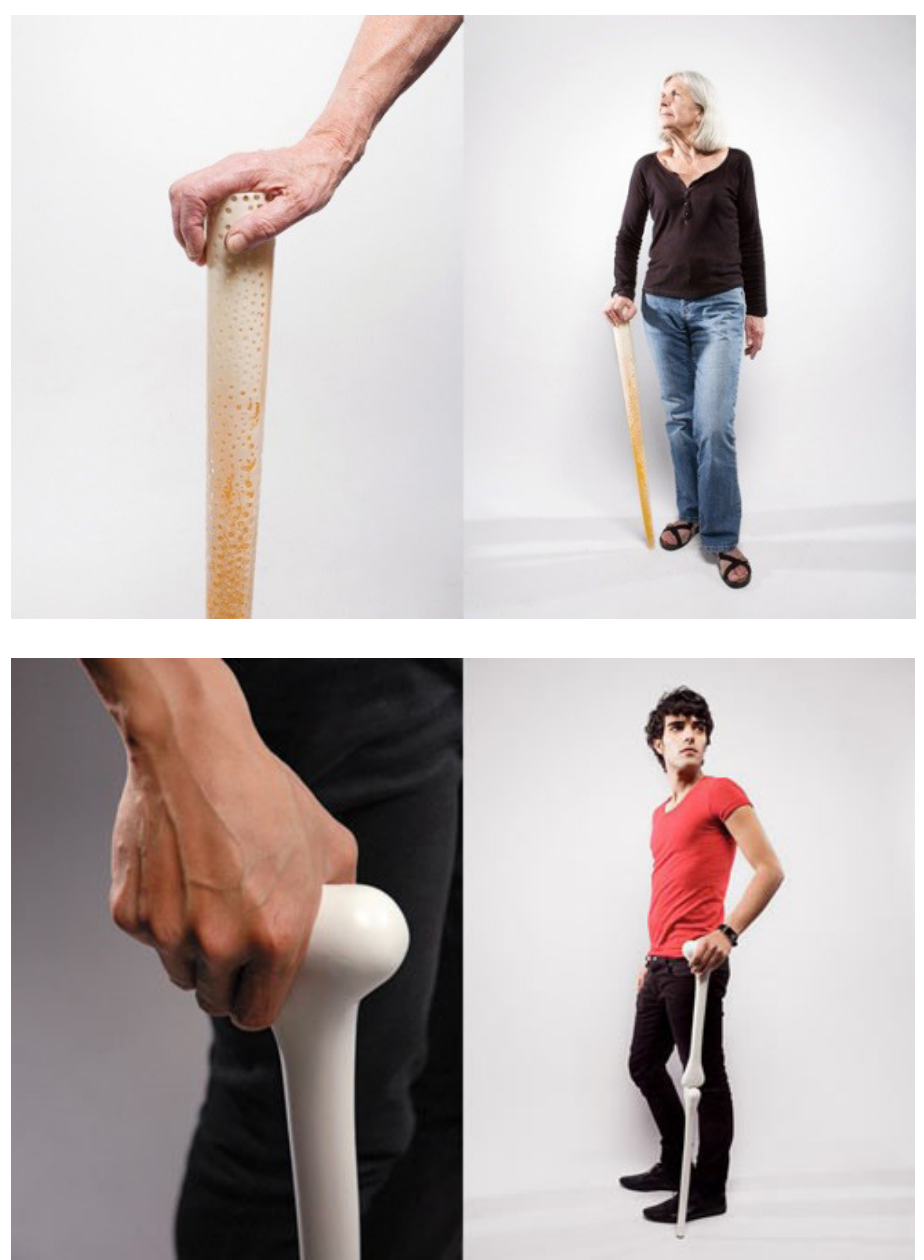

Fonte: Lanzavecchia e Wai (2018).

"Together Canes" (Bengalas Juntas) é um conjunto de três bengalas que segue a linha de produtos que abrangem propriedades de móveis e hábitos cotidianos e inclui três modelos: I-cane, com suporte para livros ou iPad; U-cane, com um recipiente para armazenar objetos em geral e T-cane, com bandeja para servir comidas e bebidas. 
Breve caminhada com uma bengala e reflexões... público sênior DAMAZIO, V. M.; ARIGONI, L. B.

Figura 8 - Together Canes: I-Cane, U-Cane e T-Cane

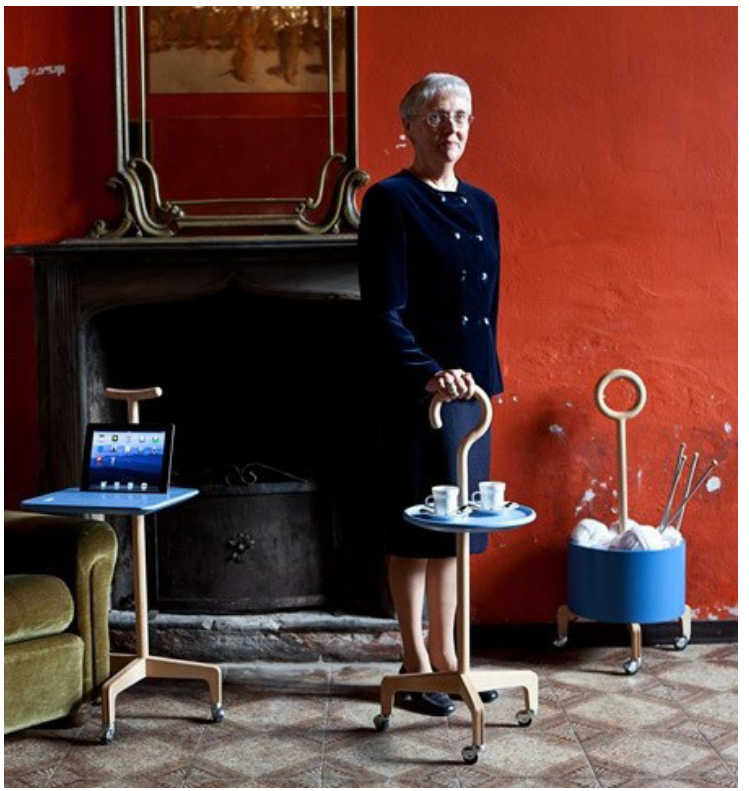

Fonte: Lanzavecchia e Wai (2018). 
Projética, Londrina, v.11, n.1, p. 220-244, abril 2020

A coleção de bengalas da dupla de designers à frente da "Lanzavecchia + Wai | Italy \& Singapore" encerra esta breve caminhada pela relação das pessoas com a bengala e - lado aos demais projetos do estúdio - fica como uma promissora abordagem para a necessária e urgente revisão crítica dos produtos que vem respondendo pelas demandas do crescente, diverso e extenso público de maiores de 60 anos. Fica, também, como exemplo das infinitas possibilidades a serem exploradas para atender aquela que vem sendo reconhecida como a geração prateada.

\section{CONSIDERAÇÕES FINAIS}

Uma das principais metas deste artigo foi demonstrar a relevância do tema envelhecimento para o campo do Design e seu potencial para contribuir com a longevidade com qualidade, a partir do projeto de novas formas de atender as demandas da população que envelhece. Como defendido acima, os produtos que usamos, estabelecem significados sobre nós mesmo e nossas vidas. Eles nos instruem acerca do mundo, organizam e regulamentam nossas práticas, influenciam nossos comportamentos e provocam efeitos reais e variados.

Apesar de diverso e crescente, o público sênior vem sendo atendido por universo material de bens e serviços reduzido e construído com foco nas demandas de parcela da população que, por questões variadas, torna-se vulnerável, dependente, sem saúde e sem autonomia e que, para efeito retórico, chamaremos de "velho velho".

Neste sentido, é vital e urgente projetar produtos para o "novo velho" e que estabelecerão novos significados sobre os integrantes da chamada geração prateada; que organizarão e regulamentarão suas novas práticas, influenciarão novos comportamentos e impactarão positivamente sua qualidade de vida. 


\section{REFERÊNCIAS}

1. BEAUVOIR, Simone. A velhice. Rio de Janeiro: Nova Fronteira, 1990.

2. BÍBLIA. Português. Bíblia sagrada online. Matosinhos: 7Graus, 2009. Disponível em: https://www.bibliaon.com/. Acesso em: 25 maio 2018.

3. BIENNAIS, Martin-Guillaume. Main de Justice. 1804. Disponível em: https:// www.louvre.fr/mediaimages/main-de-justice-regalia. Acesso em: 25 maio 2018.

4. CARDOSO, Rafael. Uma introdução à história do design. São Paulo: Blucher, 2008.

5. CERTEAU, Michel de. A invenção do cotidiano: as artes do fazer. Petrópolis: Vozes, 1994. v. 1.

6. CHEVALIER, Jean; GHEERBRNT, Alain. Dictionary of symbols. London: Penguin Books, 2009.

7. COELHO, Luiz Antônio. Tal objeto, tal dono. In: LOPES, Luiz Paulo da Moita; BASTOS, Liliana Cabral (org.). Identidades: recortes multi e interdisciplinares. São Paulo: Mercado das Letras, 2002. p. 69-81.

8. CSIKSZENTMIHALYI, Mihaly; ROCHBERG-HALTON, Eugene. The meaning of things: domestic symbols and the self. New York: Cambridge University Press, 1991. 


\section{Breve caminhada com uma bengala e reflexões... público sênior}

DAMAZIO, V. M.; ARIGONI, L. B.

18. LESTER, Katherine; OERKE, Bess Viola. Accessories of dress: an illustrated encyclopedia. New York: Dover Publications, 2004.

19. METROPOLITAN MUSEUM OF ART. The met collection. Nova lorque, US: Metropolitan Museum, 2018. Disponível em: https://www.metmuseum.org/. Acesso em: 31 maio 2018.

20. MORRISROE, Patrick. Crosier. In: CATHOLIC Encyclopedia. New York: Robert Appleton Company, 1908. v. 4. Disponível em: http://www.newadvent.org/ cathen/04515c.htm. Acesso em: 31 maio 2018.

21. MUSEUM OF FINE ARTS. Collections. Boston, MAS: Museum of Fine Arts, 2018. Disponível em: https://www.mfa.org/. Acesso em: 31 maio 2018.

22. OMS - Organização Mundial da Saúde. Lista de produtos assistivos prioritários: melhorando o acesso a tecnologias assistivas para todos, em todos os lugares. Genebra: OMS, 2017. Disponível em: https://apps.who.int/iris/ bitstream/handle/10665/207694/WHO-EMP-PHI-2016.01-por.pdf?sequence=14\&isAllowed=y. Acesso em: 31 maio 2018.

23. ROBITAILLE, Suzanne. The illustrated guide to assistive technology and devices: tools and gadgets for living independently. New York: Demos Medical Publishing, 2010.

24. ROCHE, Daniel. História das coisas banais. Lisboa: Editorial Teorema, 1998.

25. SIMON, Herbert A. The sciences of the artificial. Cambridge: The MIT Press, 1969. 
Projética, Londrina, v.11, n.1, p. 220-244, abril 2020

26. SNODGRASS, Mary Ellen. World clothing and fashion: an encyclopedia of history culture and social influence. New York: Routledge, 2014.

27. STEELE, Valerie. Encyclopedia of clothing and fashion. New York: Thomson Gale, 2005.

28. TIEPOLO, Giovanni Domenico. Mercury appears to Aeneas in a dream. 1757. 1 pintura. Disponível em: https://www.metmuseum.org/art/collection/search/362042. Acesso em: 25 maio 2018.

29. UNITED NATIONS POPULATION FUND; HELPAGE INTERNATIONAL. Envelhecimento no século XXI: celebração e desafio. Nova York: UNFPA, 2012.

30. ZAKI, Mey; PRESS, Farid Atiya. The legacy of Tutankhamun: art and history. Giza: Abydos Publications, 2007.

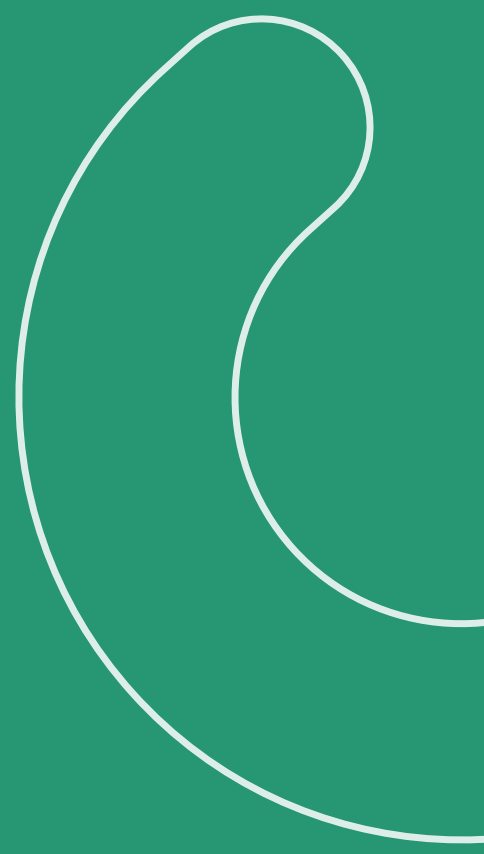

